Austral Comunicación

Volumen 9, número 2 (diciembre de 2020)

\title{
Francisco Albarello, Francisco Arri y Ana Laura García Luna. Entre libros y pantallas: los booktubers como mediadores culturales \\ Buenos Aires: Universidad del Salvador, 2020, 124 pp. ISBN 978-950-592-275-8 \\ DOI: https://doi.org/10.26422/aucom.2020.0902.par
}

En el ecosistema digital en constante transformación irrumpen diferentes actores que encuentran un área en la que instalarse y evolucionar. Es el caso de los booktubers, jóvenes apasionados por la lectura que comparten sus opiniones sobre literatura a través de la plataforma colaborativa YouTube. Este fenómeno, cuyo surgimiento puede ubicarse entre 2011 y 2012, llama la atención no sólo de los estudiosos de la comunicación sino de la propia industria editorial.

Situados en una línea de investigación que aborda la relación de los adolescentes y los jóvenes con las nuevas tecnologías desde una perspectiva que Eco llamaría integrada, Albarello, Arri y García Luna se introducen en el universo de los booktubers y explican la dinámica con la que funciona. El libro, surgido de una investigación llevada a cabo entre 2017 y 2018 en la Facultad de Ciencias de la Educación y de la Comunicación Social de la Universidad del Salvador, logra exponer las motivaciones de estos jóvenes lectores, caracterizar los intercambios que tienen con sus seguidores, mostrar la inserción de sus producciones en el mercado editorial y describir las propiedades de sus discursos.

Los resultados que la obra presenta provienen de una triangulación metodológica, que combinó la técnica de la entrevistas en profundidad con el análisis de los mensajes. Las entrevistas se realizaron a diez booktubers argentinos, a quienes los investigadores accedieron gracias a la colaboración de un equipo de alumnos más cercano al grupo etario de estos lectores. El análisis de la producción audiovisual, con una matriz de índole cualitativa y cuantitativa, permitió complementar las opiniones obtenidas con los datos de la realidad.

Lo atrayente del libro es que, en sus seis capítulos, muestra el mundo de estos nuevos mediadores culturales, como los denominan los autores, a través de su propia voz, lo que ayuda a comprender con claridad su perfil y sus acciones.

En el primer capítulo, se enmarca el fenómeno en un ámbito más amplio: el de los modos de lectura, la mediación cultural y las narrativas transmedia. Para Albarello, Arri y García Luna, estos jóvenes recuperan la lectura en voz alta de la antigüedad clásica mientras que alternan entre la lectura intensiva y la extensiva. A la vez, se encuentran a mitad de camino entre libros y pantallas: aprecian el libro papel, pero lo difunden a través de los medios digitales. En este marco, se convierten en nuevos intermediarios entre los lectores y las obras literarias, diferenciándose de los que tradicionalmente ocupan ese rol: los críticos literarios y los maestros. En cuanto a los productos que crean, los autores los consideran extensiones narrativas transmedia, ya que expanden los relatos originados en los libros en variedad de soportes, formatos y géneros, tanto en las redes sociales como en experiencias presenciales.

El segundo capítulo permite conocer los dichos de los propios booktubers. Uno de los aspectos más llamativos es que estos lectores apasionados, para quienes la lectura es una actividad lúdica, remarcan que prefieren leer 
los libros en formato papel en vez de hacerlo en la pantalla. Tener el libro en la mano, pasar las páginas, ponerlo luego en la biblioteca son partes de un rito que califican como placentero. La elección del papel también tiene relación con la posibilidad de intervenirlo con subrayados, anotaciones y marcas propias. Los autores explican que los jóvenes desarrollan así una relación personal con el objeto libro, apropiándose de él y lo que rememora a quienes comentaban al margen los códices medievales.

En el tercer capítulo, se devela cómo entienden los booktubers su rol. Ellos se definen como lectores; no leen para hacer videos sino que hacen videos porque leen. Sostienen que incluso podrían dejar de producir contenido audiovisual, pero que no dejarían de leer. Su actividad es una continuación de las recomendaciones de libros que pueden hacer en su vida diaria. Señalan que una de las características que más valoran es la autenticidad y la fidelidad a su parecer. Esto queda en evidencia al encontrarse un alto grado de autorrefencialidad en sus reseñas. Desde el lugar de la subjetividad, les hablan a sus pares sobre sus gustos, y desde allí realizan una actividad que consideran que puede ayudarlos a desarrollar capacidades útiles para su futuro.

La comunidad de lectura es el eje del capítulo cuarto. Albarello, Arri y García Luna destacan que para los booktubers la práctica individual de la lectura cobra sentido al ser compartida. Ellos conocen las reglas del juego para el desarrollo de una comunidad: se citan entre sí para generar tráfico de un canal a otro, apelando al interés de sus audiencias, y manejan todas las redes sociales para difundirse a sí mismos. YouTube funciona como su canal principal mientras que las otras redes sociales como Instagram o Twitter colaboran en la expansión de ese canal. En todos los casos, la horizontalidad de los vínculos es esencial: ellos inician el diálogo, pero la conversación es entre pares. Este capítulo también marca que los videos que crean constituyen un tipo de producción transmedia, ya que los booktubers son usuarios activos que expanden los mundos narrativos de los libros que comentan.

El quinto capítulo introduce en la relación compleja de los booktubers con el mercado editorial, que busca institucionalizar algunas de sus prácticas y hacerlos parte del canon. Los autores explican que la industria ve en ellos una forma de llegar a un público joven y, con ese objetivo, desarrolla estrategias para ponerlos de su lado: en algunos casos les brindan su catálogo de novedades para que elijan qué libro reseñar, mientras que en otras oportunidades les piden que comenten ciertas obras. Esto se hace bajo el marco de una relación de beneficio mutuo: ellos consiguen el libro gratis y las empresas ganan con la promoción que les hacen. No hay honorarios de por medio, y esto parece permitirles seguir fieles a sus gustos.

De todos modos, ellos hacen referencia a la presión que sienten al tener que comentar o al menos mostrar los libros que reciben. Tal situación lleva a que no todas sus producciones sean reseñas de libros y a que incorporen otras modalidades: Book haul (informes de los libros adquiridos en un período), Book tag (juegos en los que se responden consignas), $T B R$ o To Be Read (videos en que cuentan lo que van a leer), Book Challenge (desafíos que incluyen tiempos y puntajes), Wrap Up (videos en que muestran los libros leídos durante cierto tiempo) y Book Talk (discusión sobre un libro que puede contener spoilers).

El último capítulo repasa las características de las producciones de los booktubers. 
Austral Cmunicación

Volumen 9, número 2 (diciembre de 2020)

Ellos aprenden por su cuenta el uso de los programas a utilizar y, en general desde su cuarto, producen el material. No hay guion en sentido estricto porque privilegian la espontaneidad, Si bien en las entrevistas indican que buscan diferenciarse del lenguaje televisivo, el análisis de los videos les permite a los autores concluir que en realidad se basan en el formato del noticiero: mirada a cámara, planos medianos y angulación normal.
En síntesis, el libro resulta un aporte valioso al campo de las nuevas tecnologías de la comunicación al lograr delinear un panorama de las características y comportamientos de la comunidad de los booktubers en la Argentina. En ese marco se vuelve una fuente clave para entender esta modalidad de lectura atravesada por las posibilidades de las herramientas digitales pero anclada en la antigua costumbre de compartir lo leído.

Graciela M. Paredes

Facultad de Ciencias de la Educación y de la Comunicación Social, Universidad del Salvador Graciela.paredes@usal.edu.ar 